\title{
Measuring Hukou Amenity by Using Urban Land Price in China
}

\author{
Haoxuan Zou ${ }^{1}$ and Guannan Teng ${ }^{2}$
}

\begin{abstract}
This paper conducts an empirical study on the land supply with Chinese characteristics in terms of the most different characteristics between China and other major economies in the world, such as Hukou (household registration) system, by combining qualitative and quantitative analysis. The main purpose of this paper is to use land price to measure city amenity in China. By doing this, the spatial distribution of urban residents becomes much more understandable. This paper firstly points out the driving forces of population migration to cities are not only wages, but also cities' amenity. The paper suggests that it is important to quantify the amenity of a city to understand the specific mechanism of amenity in population flow and regional development. It is found that the amenity of Hukou of other grades is far less than that of those top cities like Beijing. The paper suggests this polarization not only causes the sense of unfairness, but also damages the free flow of elements and economic efficiency. This paper has also recommended some useful thoughts on this issue, like to remove the limitation of population in the super first tier or first tier cities to give full play to the agglomeration effect and advantages of big cities. Besides, the supply of public goods cannot be too concentrated in large cities. The government needs to constantly narrow the regional public service gap on the supply side, gradually eliminate the privileges behind Hukou, and let the Hukou system return to its original meaning.
\end{abstract}

JEL classification numbers: R20, R58.

Keywords: Hukou, Amenity, Urban Land Supply.

${ }^{1}$ PBC School of Finance, Tsinghua University.

2 Faculty of Social Science, The Chinese University of Hong Kong.

Article Info: Received: February 21, 2021. Revised: March. 20, 2021.

Published online: March 30, 2021. 


\section{Introduction}

\subsection{Amenity and Quantitative Measurement}

What is the driving force of people migrating to cities? According to the traditional theory of population migration, people transport between regions for higher wages or expected wages (Lewis, 1954). But in addition to higher wages, better environment and public services is similarly important and this is included in term 'Amenity'. Amenity is generally considered to be services or facilities for daily life such as the environment, health, education, transportation, culture, and leisure (Randall, 2008). According to Gottlieb (1995), "amenity of residents can be defined as goods or services bound to location and functioning in the utility function". Mathur et al. (2005) and McNulty et al. (1985) define amenity as "quality of living factors". Howie et al. (2010) further confirmed that "amenity is understood as how important a place is to people's perception". It is believed that the main reason for population migration among cities is the amenity of cities. The amenity of a city can be a public product provided by the government, such as environmental education and medical care. Graves (1983) found that the residents of the United States first valued income when choosing a city, but when the income increased, they would move to a city with higher amenity. Albouy et al. (2020) found that amenities determine location more than trade productivity in the United States; urban amenities can also be provided by the private sector, such as coffee shops, etc. Glaeser et al. (2001) believed that urban economics traditionally regarded the city as a place with advantages in production and disadvantage in consumption, but the importance of the city is increasingly reflected in becoming a consumption center. They found that cities with high amenity grew faster than cities with low amenity.

In order to understand the specific mechanism of amenity in population migration and regional development, to be able to quantitatively measure city amenity become very important. The measurement here is not the statistical value of PM2.5 or how many key middle schools, but it is the economic value that reflects people's preference after amenity is capitalized into asset prices in the market economy. At present, there are several mature methods to calculate the economic valuation of environmental amenity in the academic community, mainly including hedonism price model, contingent value model and travel cost model. The travel cost method is to infer the economic value of a scenic spot by using the cost of money and time spent by visitors to the scenic spot (Parsons, 1990). The travel cost method has been applied to a certain extent since it was proposed in 1966 (Garrod \& Willis, 1992). Some studies have found that the travel cost method is effective for parks and wetlands far away from the city (Sorg \& Loomis, 1984), but poor for scenic spots in the city. The main reason is that the difference in transportation cost between the users of these scenic spots to the scenic spots is small (Clawson \& Knetsch, 1966). The travel cost method has advantages in the authenticity of market economic model, collection of basic data and universality. However, in the face of time cost, non-single purpose travel, time-varying quality of scenic spots and other problems, 
this method is proved less useful (Dwyer, Peterson et al., 1983; Walsh, Bjonback et al., 1990). Therefore, this method is mainly used to measure tourists' preference for a single scenic spot with a single purpose (Smith \& Kopp, 1980).

Contingent valuation model is to conduct a questionnaire survey on urban residents and ask them the price they are willing to pay in order to protect the amenity of urban green space or environment. In 1963, Davies first used the contingent valuation model to evaluate outdoor leisure facilities in the United States (Smith, Desvousges et al., 1986). Since then, this method has been widely used in abstract amenity measurement (Venkatachalam, 2004). contingent valuation model has strong applicability and flexibility, but there are disputes on the effectiveness and reliability of the estimation results (Hausman, 2012). This is mainly because the design of the questionnaire is prone to bias and the subjective preference of the interviewees has cognitive bias, which easily leads to the distortion and objectivity of the results of the questionnaire (Tyrväinen \& Väänänen, 1998).

Since the hedonic price method was proposed by Griliches (1971) and Rosen (1974), it has become a common method of environmental and service amenity parity, and has been widely used in the evaluation of urban air quality, urban greening and amenity of transportation facilities (Rosen, 1974). As we have already introduced in the fourth chapter, the hedonic price method is based on the view that the utility of goods to consumers can be divided into the sum of the utility brought by different characteristics of goods (Braden \& Kolstad, 1991). The biggest advantage of the hedonic price method is that it uses the real market price to evaluate the appropriate human nature, which can avoid the deviation caused by the confusion between the consumers' purchase desire and the real purchase behavior in the contingent valuation model (Braden \& Kolstad, 1991). Because of its strong flexibility and wide applicability, the hedonic price model can use market transaction data reflecting the real supply and demand. This as a result make this model more scientific and reasonable than other methods. Brookshire et al. (1982) deeply compared the hedonic price method with the contingent valuation model and considered that the hedonic price method is more suitable for measuring the amenity of urban public goods.

\subsection{Urban Hukou and Public Services in China}

For China, the amenity of cities is largely reflected in the public services such as education and medical services provided by urban household registration (Xia \& Lu, 2015; Liu \& Wei, 2019). China's unique household registration system determines that citizens' rights to obtain public services such as compulsory education and medical services. The acquirement of services is largely evidenced by their local household registration status.

The Hukou, also known as household registration system, which emerged in the $1,850 \mathrm{~s}$, is a way for China to control the population flow between urban and rural areas and between cities (Cheng \& Selden, 1994). The household registration system divides the population of China into urban household and rural household. 
Before the reform and opening up, the rural population with rural household registration was not allowed to move freely to cities. Since the reform of the household registration system in the 1980s of the last century, the original stringent restrictions have been relaxed, and people can work and live in cities, which is also one of the main driving forces of urbanization. People who work and live in cities but do not have local household registration are referred to as 'mobile population'. Although the restrictions on free migration in the household registration system have been continuously weakened in previous reforms since the 1990s (Zhu \& Chen, 2010). The social welfare system linked to the household registration system has not changed. The mobile population without local household registration cannot enjoy the same quality public services in the city as the people with local household registration.

The public services linked to urban household registration in China are mainly concerned with educational resources and medical resources. According to the results of China's dynamic monitoring survey on mobile population in 2017, better education opportunities for children has become the main reason for the mobile population to intend to stay in the local area, and personal development and income growth retreat are the secondary reasons; Liao et al. (2019) found that the mobile population from rural to urban places the most emphasis on urban medical services.

\subsection{Necessary Conditions for Obtaining the Permanent Urban Residence Certificate (Hukou) - Housing Property Ownership}

In this essay, we study and discuss the urban household registration but not the collective household registration. Buying a house is a necessary precondition for acquiring the permanent urban residence certificate. Although employees employed by the company in cities may also have "household accounts", they are collective household accounts. The social benefits linked to the collective household accounts cannot be compared with the resident household accounts at all. Once the contract is terminated, the household accounts need to be moved back. The collective household accounts cannot pay the social security by themselves, while the resident household accounts can be paid by themselves. Moreover, if the parents are collective household accounts, the children will not enjoy the benefits of compulsory education in that region and is not counted as student status. However, as long as the holders of collective accounts buy a house in the city, they can go through the household registration formalities with the local neighborhood committee. Ownership of a house is thus necessary for getting a local resident household account.

Even in some cities, in order to promote the sale of real estate, they can directly settle down as long as they buy a house. Major cities such as Beijing and Shanghai had introduced the policy of directly settling down by purchasing houses in cities around 2000, which was later canceled; many cities in China have successively launched the policy of "settling down by purchasing houses" around 2009. This shows the role of buying a house: only by purchasing a house in the city can we 
obtain the children's education (high-quality education and college entrance examination Bonus), employment opportunities, social welfare and medical benefits brought by the household registration.

\subsection{Summary}

Based on the previous analysis, we will use the hedonic price model to measure the amenity of public services brought by urban household registration in China and compare the amenity differences between different levels of cities by using the price difference of residential land that can be settled and that cannot be settled. It is found that the amenity of urban household registration in other levels is much less than that of registration in super first tier cities such as Beijing, Shanghai, Guangzhou and Shenzhen.

The following chapters are arranged as follows: the second section introduces the research methods, model settings and data, the third section introduces the main results, and the fourth section summarizes.

\section{Research Design}

\subsection{Characteristic Facts}

Due to the fact that the land is state-owned, the land sold for different purposes in cities in China has a corresponding term. According to the twelfth article of the Provisional Regulations of the People's Republic of China on the assignment and transfer of the right to the use of state owned land in cities and towns, the maximum term of the assignment of the right to the use of land shall be determined according to the maximum prescribed term of the use, and only residential land shall be regulated as 70 years, and other land shall be 50 years or less (the State Council, 19 May 1990). Generally speaking, residential land is 70 years, commercial land is 40 years and industrial land is 50 years. However, land for the same purpose is not always sold according to a fixed year. Residential land is not only sold for a term of 70 years (the longest), but also sold for a term of 40 years and 50 years. For the houses on the residential land, the houses less than 70 years are generally of commercial nature, such as apartment houses; the houses with 70 years are generally civil housing, i.e. ordinary commercial housing. According to the Chinese law, only the hotel apartment with a term of 70 years or property right of residential land can meet the standard of settlement. The micro land supply documents on the land market of China all have term and purpose, so this provides a factual basis for us to distinguish the land parcels of 70 years and non 70 years in residential land. 


\subsection{Empirical Model Setting}

We suppose land price and distance are assumed to be exponential relationship, and the benchmark model is set as follows:

$$
p_{i=} \theta e^{\rho u_{i}}
$$

Here $\boldsymbol{p}_{\boldsymbol{i}}$ is the unit price of land at location $\boldsymbol{i}, \boldsymbol{u}_{\boldsymbol{i}}$ is the distance from location $\boldsymbol{i}$ to the city center, $\boldsymbol{\theta}$ is the land price of the city center, and $\boldsymbol{p}$ is the changing curvature of the price relative to the distance from the city center. The hedonic price regression model of price-distance function can be obtained by re-writing formula (1):

$$
\ln \left(p_{i}\right)=\ln (\theta)+\rho u_{i}
$$

Since our micro land price data includes land price data of different distances from the city center, we can obtain formula (3) through simple regression based on formula (2), where $\beta_{0}$ and $\beta_{1}$ are estimates of $\ln (\theta)$ and $\rho$.

$$
\ln \left(p_{i}\right)=\beta_{0}+\beta_{1} u_{i}+\varepsilon_{i}
$$

We add the dummy variable $\boldsymbol{d}_{\boldsymbol{j}}$ to obtain the regression equation (4), in which $\boldsymbol{i}$ represents land plot and $\boldsymbol{j}$ represents city. If the transfer period of this residential land is 70 years, then $\boldsymbol{d}_{\boldsymbol{i} \boldsymbol{j}}=1$, and if it is less than 70 years, then $\boldsymbol{d}_{\boldsymbol{i} \boldsymbol{j}}=0$.

$$
\ln \left(\mathrm{p}_{i j}\right)=\beta_{0}+\beta_{1} D_{i j}+\beta_{2} u_{i j}+\beta_{3} u_{i j} * Y_{j}+\beta_{4} u_{i j} * H_{j}+\varepsilon_{l}
$$

Formula (4) is the hedonism price regression equation that we use to measure the amenity of urban household registration. Regression coefficient $\beta_{1}$ means that the land price of residential land that can be settled is $\boldsymbol{e}^{\boldsymbol{\beta} \mathbf{1}}$ times of that of residential land that cannot be settled.

\subsection{Sample selection and data source}

Specifically, we selected the residential land, which was sold by bidding, auction and hanging on the land market from 2007 to 2016 and not more than 50 kilometers away from the city center. As there are many land parcels with residential use in the data with a transfer term of "residential 70 years, commercial 40 years", that is to say, mixed commercial and residential, but the proportion of residential is high, and the overall definition is not clear. Therefore, in the existing data, we only select land parcels with a transfer term of 70 years, 40 years or 50 years, and 70 years is residential land parcels. If it is less than 70 years, it will be non-residential land, and will not be mixed with residential land. Table 1, table 2 , table 3 and table 4 are the description statistics of super first-tier cities, first-tier cities, second-tier cities, and third-tier cities, respectively. The sample data of non-residential land is still 
relatively large, and the data is sufficient for regression analysis. At the same time, there is no extreme value to be dealt with.

Table 1: Description statistics: Super first-tier cities

\begin{tabular}{|c|c|c|c|c|}
\hline & \multicolumn{2}{|c|}{70 years } & \multicolumn{2}{|c|}{ Not 70 years } \\
\hline & $\begin{array}{l}\text { Land price } \\
\left(\text { yuan } / m^{2}\right)\end{array}$ & Distance (km) & $\begin{array}{l}\text { Land price } \\
\left(\text { yuan } / m^{2}\right)\end{array}$ & Distance $(\mathbf{k m})$ \\
\hline Sample size & 864 & 864 & 101 & 101 \\
\hline Mean value & 15867.13 & 25.60 & 2890.14 & 26.04 \\
\hline Standard error & 17916.93 & 10.80 & 4556.65 & 11.48 \\
\hline Minimum value & 52.64 & 2.18 & 59.93 & 6.40 \\
\hline 25 percentiles & 3203.61 & 17.53 & 478.53 & 18.00 \\
\hline Median & 9646.08 & 24.81 & 648.55 & 23.39 \\
\hline 75 percentiles & 20955.64 & 33.53 & 2993.35 & 31.48 \\
\hline Maximum value & 99204.86 & 49.36 & 15000.12 & 45.06 \\
\hline
\end{tabular}

Table 2: Description statistics: First-tier cities

\begin{tabular}{|c|c|c|c|c|}
\hline \multirow{2}{*}{} & \multicolumn{2}{|c|}{ 70 years } & \multicolumn{2}{c|}{ Not 70 years } \\
\cline { 2 - 5 } & $\begin{array}{c}\text { Land price } \\
\left(\mathbf{y u a n} \mathbf{m}^{\mathbf{2}}\right)\end{array}$ & Distance (km) & $\begin{array}{c}\text { Land price } \\
\left(\mathbf{y u a n} \mathbf{m}^{\mathbf{2}}\right)\end{array}$ & Distance (km) \\
\hline Sample size & 3097 & 3097 & 1246 & 1246 \\
\hline Mean value & 5142.62 & 22.41 & 4288.83 & 17.20 \\
\hline Standard error & 7818.42 & 13.30 & 4578.81 & 10.52 \\
\hline Minimum value & 80.51 & 0.01 & 77.30 & 0.01 \\
\hline 25 percentiles & 1135.01 & 11.34 & 1356.72 & 10.28 \\
\hline Median & 2404.64 & 21.82 & 3061.01 & 14.93 \\
\hline 75 percentiles & 5479.94 & 32.31 & 5445.36 & 20.47 \\
\hline Maximum value & 67306.07 & 49.44 & 64720.46 & 48.85 \\
\hline
\end{tabular}


Table 3: description statistics: Second-tier cities

\begin{tabular}{|c|c|c|c|c|}
\hline \multirow{2}{*}{} & \multicolumn{2}{|c|}{ 70 years } & \multicolumn{2}{c|}{ Not 70 years } \\
\cline { 2 - 5 } & $\begin{array}{c}\text { Land price } \\
\left(\mathbf{y u a n} \mathbf{m}^{\mathbf{2}} \text { ) }\right.\end{array}$ & Distance (km) & $\begin{array}{c}\text { Land price } \\
\left(\mathbf{y u a n} / \mathbf{m}^{\mathbf{2}} \text { ) }\right.\end{array}$ & Distance (km) \\
\hline Sample size & 3357.00 & 3357.00 & 186.00 & 186.00 \\
\hline Mean value & 4242.15 & 20.80 & 2884.49 & 19.49 \\
\hline Standard error & 6425.18 & 12.74 & 6812.90 & 14.14 \\
\hline Minimum value & 60.09 & 0.26 & 94.05 & 0.69 \\
\hline 25 percentiles & 842.95 & 10.66 & 522.92 & 8.69 \\
\hline Median & 2135.56 & 17.98 & 1499.97 & 13.13 \\
\hline 75 percentiles & 4922.19 & 30.69 & 3422.90 & 33.03 \\
\hline Maximum value & 66322.55 & 49.76 & 85796.33 & 49.69 \\
\hline
\end{tabular}

Table 4: description statistics: Third-tier cities

\begin{tabular}{|c|c|c|c|c|}
\hline \multirow{2}{*}{} & \multicolumn{2}{|c|}{ 70 years } & \multicolumn{2}{c|}{ Not 70 years } \\
\cline { 2 - 5 } & $\begin{array}{c}\text { Land price } \\
\left(\mathbf{y u a n} / \mathbf{m}^{\mathbf{2}}\right)\end{array}$ & Distance (km) & $\begin{array}{c}\text { Land price } \\
\left(\mathbf{y u a n} / \mathbf{m}^{\mathbf{2}}\right)\end{array}$ & Distance (km) \\
\hline Sample size & 6682.00 & 6682.00 & 430.00 & 430.00 \\
\hline Mean value & 1659376 & 20.37 & 1053.05 & 20.09 \\
\hline Standard error & 1686.23 & 15.85 & 1442.33 & 15.42 \\
\hline Minimum value & 58.12 & 0.01 & 69.00 & 0.01 \\
\hline 25 percentiles & 600.00 & 5.07 & 300.00 & 6.88 \\
\hline Median & 1125.31 & 17.99 & 600.52 & 14.94 \\
\hline 75 percentiles & 2165.73 & 34.36 & 1144.08 & 33.77 \\
\hline Maximum value & 17465.22 & 49.75 & 15231.61 & 49.48 \\
\hline
\end{tabular}

\section{Main Results and Robustness Test}

\subsection{Main Results}

Table 5 is the result of hedonic price regression. The result shows that all coefficients are statistically significant at least at the 95\% level. The regression coefficients of the dummy variable representing whether it is residential land in the full-variable hedonic price regression model of super first-tier, first-tier, second tier 
and third-tier cities are $1.45,0.6,0.57$ and 0.37 , respectively. This shows that the land price of residential land that can be settled in these 4 tier cities is $\boldsymbol{e}^{\mathbf{1 . 4 5}} \approx \mathbf{4 . 3}$ times, $e^{0.6} \approx 1.8$ times, $e^{0.57} \approx 1.7$ times and $e^{0.37} \approx \mathbf{1 . 4}$ times of the land price of non-residential land that cannot be settled. This result reflects that the amenity of urban household registration in super first-tier cities such as Beijing, Shanghai, Guangzhou, and Shenzhen are higher than other tier cities. This partly explains why in the fourth chapter of the housing price index, the housing prices in the super first-tier cities are soaring, and in the fifth chapter of the hedonic price regression, the housing prices in the center of the super first-tier cities are more than ten times of those in other cities. If the monetary value of human nature of urban household is considered, the difference of land price between the land that can be settled and the land that cannot be settled is also different under the setting of a semi index model $\boldsymbol{p}=\boldsymbol{p}_{\mathbf{0}} \boldsymbol{e}^{-\boldsymbol{\beta} \boldsymbol{u}}$. Under the existing settings, we can see the land price difference of the city center. As a super first-tier city, the land price difference of Beijing, Shanghai, Guangzhou and Shenzhen is $\boldsymbol{e}^{7.98} *(4.3-1) \approx \mathrm{RMB} 9640$, the land price difference of the first-tier city is $\boldsymbol{e}^{\mathbf{8 . 6 2} *}(1.8-1) \approx \mathrm{RMB} 4430$, the land price difference of the second-tier city is $\boldsymbol{e}^{7.71 *(1.7-1)} \approx \mathrm{RMB} 1560$, and the land price difference of the third-tier city is $\boldsymbol{e}^{\mathbf{6 . 6 4} *}(1.4-1) \approx \mathrm{RMB} 300$. In addition, from the constant regression coefficient of the hedonic price regression, it can be found that the land price of the urban center of the super first-tier city is even lower than the land price of the residential center of the first-tier city. This proves that the population flowing into the super first-tier city is quite dependent on the public services such as high-quality education and medical services in the major cities, and the monetary value of this public service accounts for a large proportion of the land price.

Next, we calculate the price difference between a house that can be settled in the city center and a house that cannot be settled. According to the "Several Opinions on Implementing the Proportion Requirements of New Housing Structure" issued by the Ministry of construction in 2006, from 1 June 2006, for the newly approved and newly started commercial housing construction, the proportion of housing (including affordable housing) with a gross floor area of less than 90 square meters must reach $70 \%$ of the total area of development and construction (Ministry of housing and urban rural development, 2,006). Therefore, it can be reasonably assumed that the average housing area is 90 square meters. Under the assumption that the average floor area ratio of all buildings is 2 (which is a relatively extreme assumption, and the general floor area ratio is about 1.5), the minimum price difference of a house is: Super first-tier cities are $9640 * 90 / 2 \approx \mathrm{RMB} 434,000$, first-tier cities are $4430 * 90 / 2 \approx \mathrm{RMB} 200,000$, second-tier cities are $1560 * 90 / 2$ $\approx \mathrm{RMB} 70,000$, and third-tier cities are $300 * 90 / 2 \approx \mathrm{RMB} 13,500$. The economic value of amenity of urban household registration in super first-tier cities is 32 times of that in third-tier cities, at least RMB400,000 higher than that in third tier cities. This phenomenon indicates that there is a mismatch of public service resources among cities in China, and the polarization of public services in large cities in China 
is very serious.

The household registration system is essentially a reflection of the scarcity of public resources of relatively large population scale in China's cities at the early stage of development (Zhao \& Howden-Chapman, 2010).After the reform and opening up, although the government has invested in public services, the relative population inflow is also increasing, and the contradiction is still obvious. Our research shows that the imbalance of public service resources in Chinese cities is serious and has been slightly relieved between 2012 and 2016.

In the process of China's urbanization, a large number of population gathered in large cities far exceeds the planning setting of the initial government, while the supply of urban infrastructure and public services is still based on the population size many years ago, which makes large cities face enormous pressure on the supply of infrastructure and public services. This ultimately leads to the unnecessary resource mismatch. However, at present, the government has a very controversial way to alleviate the pressure of big cities, which is to use construction land indicators and household registration to limit economic and population agglomeration. It controls the population inflow of big cities, especially mega cities, and in turn, develop small and medium-sized cities to guide the population inflow (Xia \& Lu, 2015). In fact, many people migrate to pursue better public services. The imbalance of public service space will lead to the soaring housing prices in cities (Liang \& Tang, 2008), thus squeezing out the labor force gathered in big cities due to employment and income, resulting in the loss of urban TFP. Compared with simple restrictive policies, the equalization of public services among cities and more financial investment in education for small and medium-sized cities are more likely to ease the trend of population agglomeration that yearns for public services and promote the realization of scientific and reasonable urbanization. 
Table 5: Hedonic price regression of residential land

\begin{tabular}{|c|c|c|c|c|c|c|c|c|}
\hline & \multicolumn{2}{|c|}{ Super first tier } & \multicolumn{2}{|c|}{ First tier } & \multicolumn{2}{|c|}{ Second tier } & \multicolumn{2}{|c|}{ Third tier } \\
\hline Intercept & $7.98 * * *$ & $8.21 * * *$ & $8.62 * * *$ & $8.59 * * *$ & $7.71 * * *$ & $7.56 * * *$ & $6.64 * * *$ & $6.69 * * *$ \\
\hline & $(0.427)$ & $(0.38)$ & $(0.035)$ & $(0.035)$ & $(0.095)$ & $(0.09)$ & $(0.046)$ & $(0.047)$ \\
\hline \multirow[t]{2}{*}{$\mathrm{D}$} & $2.01 * * *$ & $1.82 * * *$ & $0.45 * * *$ & $0.60 * * *$ & $0.401 * * *$ & $0.57 * * *$ & $0.55 * * *$ & $0.49 * * *$ \\
\hline & $(0.415)$ & $(0.37)$ & $(0.03)$ & $(0.037)$ & $(0.092)$ & $(0.087)$ & $(0.046)$ & $(0.045)$ \\
\hline \multirow[t]{2}{*}{$\mathrm{u}$} & $-0.042 * * *$ & $-0.14 * * *$ & $-0.041 * * *$ & $-0.087 * * *$ & $-0.024 * * *$ & $-0.005 * * *$ & $-0.01 * * *$ & $-0.02 * * *$ \\
\hline & $(0.004)$ & $(0.008)$ & $(0.001)$ & $(0.003)$ & $(0.002)$ & $(0.003)$ & $(0.001)$ & $(0.001)$ \\
\hline$u^{*} \mathrm{Y}$ & \multicolumn{2}{|c|}{$7.09 \mathrm{e}^{-3} * * *$} & \multicolumn{2}{|c|}{$3.71 \mathrm{e}^{-3} * * *$} & \multicolumn{2}{|c|}{$5.5 \mathrm{e}^{-3} * * *$} & \multicolumn{2}{|c|}{$2.16 \mathrm{e}^{-3} * * *$} \\
\hline & \multicolumn{2}{|c|}{$\left(5.09 \mathrm{e}^{-4}\right)$} & \multicolumn{2}{|c|}{$\left(1.89 \mathrm{e}^{-4}\right)$} & \multicolumn{2}{|c|}{$\left(2.49 \mathrm{e}^{-4}\right)$} & \multicolumn{2}{|c|}{$\left(1.76 \mathrm{e}^{-4}\right)$} \\
\hline \multirow[t]{2}{*}{$\mathrm{u}^{*} \mathrm{H}$} & \multicolumn{2}{|c|}{$1.49 e^{-5 * * *}$} & \multicolumn{2}{|c|}{$1.84 e^{-5 * * *}$} & \multicolumn{2}{|c|}{$-6.33 e^{-5} * * *$} & \multicolumn{2}{|c|}{$-6.07 \mathrm{e}^{-6} * * *$} \\
\hline & \multicolumn{2}{|c|}{$\left(2.95 \mathrm{e}^{-6}\right)$} & \multicolumn{2}{|c|}{$\left(1.24 \mathrm{e}^{-6}\right)$} & \multicolumn{2}{|c|}{$\left(8.06 \mathrm{e}^{-6}\right)$} & \multicolumn{2}{|c|}{$\left(4.81 \mathrm{e}^{-6}\right)$} \\
\hline $\mathrm{R}^{2}$ & 0.45 & 0.69 & 0.42 & 0.65 & 0.51 & 0.7 & 0.53 & 0.69 \\
\hline $\begin{array}{c}\text { Sample } \\
\text { size }\end{array}$ & 875 & 875 & 4324 & 4324 & 3543 & 3543 & 7112 & 7112 \\
\hline
\end{tabular}

Note: $\mathrm{D}$ represents whether it is a residential land that can be settled down, $\mathrm{u}$ represents the distance to the urban center, $\mathrm{u}^{*} \mathrm{Y}$ represents the cross term of distance and income, and $\mathrm{u}^{*} \mathrm{H}$ represents the cross term of distance and population size. $* * *, * * *$ and. indicates the significance level of the statical result at $0.1 \%, 1 \%, 5 \%$ and $10 \%$, respectively, with standard errors in brackets.

\subsection{Robustness Test}

We adopt 2 methods to test the robustness. The first is to change spherical hypothesis of error term to City-Year double cluster error, and the second is to divide 2007 to 2016 into 2-time intervals: 2007 to 2011 and 2012 to 2016 for regression test respectively.

We start with the first method. In this article, when calculating the land price index by using the hedonic price regression model, the price index of each year should be calculated originally, and the fixed effects cannot be used. Therefore, after giving up the spherical hypothesis, the one-dimensional clustering assumption of variance covariance matrix of residuals cannot be adopted but the two-dimensional clustering assumption. At the same time, there are great differences between different urban levels in China, and the differences between years in the process of rapid urbanization are also significant. Therefore, it is more necessary to adopt City-Year double clustering for robust estimation. According to Cameron et al. (Cameron \& Miller, 2015), assuming that the regression model is $\boldsymbol{y}=\boldsymbol{x}^{\prime} \boldsymbol{\beta}+\boldsymbol{u}$, the variance 
of double robust regression is:

$$
\hat{\mathrm{V}}_{2 w_{a y}}[\hat{\beta}]=\hat{V}_{1}[\hat{\beta}]+\hat{V}_{2}[\hat{\beta}]-\hat{V}_{1 \cap 2}[\hat{\beta}]
$$

Where $\mathrm{V}$ represents variance covariance matrix of error term, $\hat{V}_{1}[\hat{\beta}]$ represents the variance matrix of the first cluster, $\hat{V}_{2}[\hat{\beta}]$ represents the variance matrix of the second cluster, and $\hat{V}_{1 \cap 2}[\hat{\beta}]$ represents the cluster variance matrix after the two clusters intersect. According to the above formula, we add double clustering error structure of city and year to the previous hedonic price regression model for reestimation. Table 6 is the result of hedonic price regression of robust standard error of double clustering. All regression coefficients are still significant and there is no significant difference from the previous results.

Table 6: residential land - Robust

\begin{tabular}{|c|c|c|c|c|c|c|c|c|}
\hline & \multicolumn{2}{|c|}{ Super first tier } & \multicolumn{2}{|c|}{ First tier } & \multicolumn{2}{|c|}{ Second tier } & \multicolumn{2}{|c|}{ Third tier } \\
\hline \multirow[t]{2}{*}{ Intercept } & $7.98 * * *$ & $8.21 * * *$ & $8.62 * * *$ & $8.59 * * *$ & $7.71 * * *$ & $7.56 * * *$ & $6.64 * * *$ & $6.69 * * *$ \\
\hline & $(0.467)$ & $(0.41)$ & $(0.27)$ & $(0.27)$ & $(0.382)$ & $(0.22)$ & $(0.195)$ & $(0.195)$ \\
\hline \multirow[t]{2}{*}{$\mathrm{D}$} & $2.01 * * *$ & $1.82 * * *$ & $0.43^{*}$ & $0.61 *$ & 0.401 & $0.57 * *$ & $0.55 * * *$ & $0.49 * *$ \\
\hline & $(0.51)$ & $(0.39)$ & $(0.09)$ & $(0.09)$ & $(0.123)$ & $(0.21)$ & $(0.151)$ & $(0.16)$ \\
\hline \multirow[t]{2}{*}{$\mathrm{u}$} & $-0.042 * * *$ & $-0.14 * * *$ & $-0.041 * * *$ & $-0.087 * * *$ & $-0.024 * * *$ & $-0.005 * *$ & $-0.01 * * *$ & $-0.02 * * *$ \\
\hline & $(0.005)$ & $(0.01)$ & $(0.005)$ & (0.004) & $(0.006)$ & $(0.02)$ & $(0.002)$ & $(0.001)$ \\
\hline \multirow[t]{2}{*}{$\mathrm{u}^{*} \mathrm{Y}$} & \multicolumn{2}{|c|}{$7.09 \mathrm{e}^{-3} * *$} & \multicolumn{2}{|c|}{$3.71 \mathrm{e}^{-3} * *$} & \multicolumn{2}{|c|}{$5.5 \mathrm{e}^{-3} * * *$} & \multicolumn{2}{|c|}{$2.16 \mathrm{e}^{-3} *$} \\
\hline & \multicolumn{2}{|c|}{$\left(2.68 \mathrm{e}^{-3}\right)$} & \multicolumn{2}{|c|}{$\left(1.18 \mathrm{e}^{-3}\right)$} & \multicolumn{2}{|c|}{$\left(1.39 \mathrm{e}^{-3}\right)$} & \multicolumn{2}{|c|}{$\left(8.97 e^{-4}\right)$} \\
\hline \multirow[t]{2}{*}{$\mathrm{u}^{*} \mathrm{H}$} & \multicolumn{2}{|c|}{$1.49 e^{-5 * * *}$} & \multicolumn{2}{|c|}{$1.84 e^{-5 * * *}$} & \multicolumn{2}{|c|}{$-6.33 e^{-5} *$} & \multicolumn{2}{|c|}{$-6.07 e^{-6}$} \\
\hline & \multicolumn{2}{|c|}{$\left(4.08 \mathrm{e}^{-6}\right)$} & \multicolumn{2}{|c|}{$\left(4.75 e^{-6}\right)$} & \multicolumn{2}{|c|}{$\left(2.59 e^{-5}\right)$} & \multicolumn{2}{|c|}{$\left(* 2.2 e^{-5}\right)$} \\
\hline $\mathrm{R}^{2}$ & 0.44 & 0.68 & 0.41 & 0.69 & 0.52 & 0.71 & 0.52 & 0.75 \\
\hline $\begin{array}{c}\text { Sample } \\
\text { size }\end{array}$ & 875 & 875 & 4324 & 4324 & 3543 & 3543 & 7112 & 7112 \\
\hline
\end{tabular}

Note: D represents whether it is a residential land that can be settled down, $\mathrm{u}$ represents the distance to the urban center, $\mathrm{u}^{*} \mathrm{Y}$ represents the cross term of distance and income, and $\mathrm{u}^{*} \mathrm{H}$ represents the cross term of distance and population size. $* * *, * * *$ and. indicates the significance level of the statical result at $0.1 \%, 1 \%, 5 \%$ and $10 \%$, respectively, with standard errors in brackets.

Table 7 and table 8 are the results of the hedonic price regression using the second methods for 2007 - 2011 and 2012 - 2016, respectively. All the regression coefficients are still significant at the $95 \%$ level. However, we can find that the regression coefficient of the dummy variable D for all the city levels in 2012 - 2016 
is smaller. Although the super first-tier cities are still the highest, the other cities are not much different. This may indicate that the reform of household registration system allows the mobile population without household registration to have access to the previously inaccessible public services. This includes the introduction of policies that allow their children to go to school nearby even if they rent a house. It also indicates that from 2012 to 2016, when other cities gradually developed, the public service resources represented by urban household registration become more balanced in the way of how it is distributed.

Table 7: 2007-2011 residential land

\begin{tabular}{|c|c|c|c|c|c|c|c|c|}
\hline & \multicolumn{2}{|c|}{ Super first tier } & \multicolumn{2}{|c|}{ First tier } & \multicolumn{2}{|c|}{ Second tier } & \multicolumn{2}{|c|}{ Third tier } \\
\hline Intercept & $7.98 * * *$ & $7.92 * * *$ & $8.24 * * *$ & $8.21 * * *$ & $7.25 * * *$ & $7.56^{* * *}$ & $6.52 * * *$ & $6.57 * * *$ \\
\hline & $(0.44)$ & $(0.42)$ & $(0.05)$ & $(0.05)$ & $(0.114)$ & $(0.22)$ & $(0.06)$ & $(0.06)$ \\
\hline \multirow[t]{2}{*}{$\mathrm{D}$} & $1.51 * * *$ & $1.45 * * *$ & $0.43 * * *$ & $0.60 * * *$ & 0.625 & $0.57 * *$ & $0.426^{* * *}$ & $0.37 * *$ \\
\hline & $(0.42)$ & $(0.41)$ & $(0.05)$ & $(0.05)$ & $(0.116)$ & $(0.21)$ & $(0.06)$ & $(0.06)$ \\
\hline \multirow[t]{2}{*}{$\mathrm{u}$} & $-0.043 * * *$ & $-0.18 * * *$ & $-0.039 * * *$ & $-0.079 * * *$ & $-0.026 * * *$ & $-0.005^{* *}$ & $-0.01 * * *$ & $-0.02 * * *$ \\
\hline & $(0.006)$ & $(0.02)$ & $(0.002)$ & $(0.004)$ & $(0.002)$ & $(0.02)$ & $(0.001)$ & $(0.002)$ \\
\hline \multirow[t]{2}{*}{$\mathrm{u}^{*} \mathrm{Y}$} & \multicolumn{2}{|c|}{$1.47 e^{-2 * * *}$} & \multicolumn{2}{|c|}{$3.29 \mathrm{e}^{-3} * *$} & \multicolumn{2}{|c|}{$5.5 \mathrm{e}^{-3} * * *$} & \multicolumn{2}{|c|}{$2.98 \mathrm{e}^{-3} * * *$} \\
\hline & \multicolumn{2}{|c|}{$\left(2.42 \mathrm{e}^{-3}\right)$} & \multicolumn{2}{|c|}{$\left(3.42 \mathrm{e}^{-4}\right)$} & \multicolumn{2}{|c|}{$\left(1.39 e^{-3}\right)$} & \multicolumn{2}{|c|}{$\left(3.36 \mathrm{e}^{-4}\right)$} \\
\hline \multirow[t]{2}{*}{$\mathrm{u}^{*} \mathrm{H}$} & \multicolumn{2}{|c|}{$1.25 e^{-5} *$} & \multicolumn{2}{|c|}{$2.48 e^{-5} * * *$} & \multicolumn{2}{|c|}{$-6.33 e^{-5} *$} & \multicolumn{2}{|c|}{$-2.39 e^{-5 * *}$} \\
\hline & \multicolumn{2}{|c|}{$\left(4.99 \mathrm{e}^{-6}\right)$} & \multicolumn{2}{|c|}{$\left(2.85 \mathrm{e}^{-6}\right)$} & \multicolumn{2}{|c|}{$\left(2.59 e^{-5}\right)$} & \multicolumn{2}{|c|}{$\left(7.93 \mathrm{e}^{-6}\right)$} \\
\hline $\mathrm{R}^{2}$ & 0.47 & 0.71 & 0.45 & 0.64 & 0.43 & 0.65 & 0.51 & 0.68 \\
\hline $\begin{array}{c}\text { Sample } \\
\text { size }\end{array}$ & 493 & 493 & 2166 & 2166 & 1620 & 1620 & 3183 & 3183 \\
\hline
\end{tabular}

Note: $\mathrm{D}$ represents whether it is a residential land that can be settled down, $u$ represents the distance to the urban center, $\mathrm{u}^{*} \mathrm{Y}$ represents the cross term of distance and income, and $\mathrm{u}^{*} \mathrm{H}$ represents the cross term of distance and population size. $* * *, * * *$ and. indicates the significance level of the statical result at $0.1 \%, 1 \%, 5 \%$ and $10 \%$, respectively, with standard errors in brackets. 
Table 8: 2012-2016 residential land

\begin{tabular}{|c|c|c|c|c|c|c|c|c|}
\hline & \multicolumn{2}{|c|}{ Super first tier } & \multicolumn{2}{|c|}{ First tier } & \multicolumn{2}{|c|}{ Second tier } & \multicolumn{2}{|c|}{ Third tier } \\
\hline Intercept & $10.36^{* * *}$ & $10.52 * * *$ & $9.01 * * *$ & $9.04 * * *$ & $8.67 * * *$ & $8.27 * * *$ & $6.95 * * *$ & $6.96 * * *$ \\
\hline & $(0.77)$ & $(0.78)$ & $(0.05)$ & $(0.05)$ & $(0.16)$ & $(0.15)$ & $(0.08)$ & $(0.07)$ \\
\hline \multirow[t]{2}{*}{$\mathrm{D}$} & 0.72 . & 0.77 . & $0.08 *$ & 0.05 . & $0.12 *$ & 0.1 . & $0.23 * * *$ & $0.2 * *$ \\
\hline & (0.13) & (0.19) & $(0.02)$ & $(0.02)$ & $(0.05)$ & $(0.03)$ & $(0.06)$ & $(0.07)$ \\
\hline \multirow[t]{2}{*}{$\mathrm{u}$} & $-0.048 * * *$ & $-0.037 * * *$ & $-0.041 * * *$ & $-0.072 * * *$ & $-0.023 * * *$ & $-0.053 * * *$ & $-0.01 * * *$ & $-0.01 * * *$ \\
\hline & $(0.006)$ & $(0.02)$ & $(0.002)$ & $(0.004)$ & $(0.002)$ & $(0.02)$ & $(0.001)$ & $(0.002)$ \\
\hline \multirow[t]{2}{*}{$\mathrm{u}^{* \mathrm{Y}}$} & \multicolumn{2}{|c|}{$-8.51 \mathrm{e}^{-4}$} & \multicolumn{2}{|c|}{$2.61 \mathrm{e}^{-3} * *$} & \multicolumn{2}{|c|}{$4.26 \mathrm{e}^{-3} * * *$} & \multicolumn{2}{|c|}{$1.96 \mathrm{e}^{-4} * * *$} \\
\hline & \multicolumn{2}{|c|}{$\left(5.29 \mathrm{e}^{-4}\right)$} & \multicolumn{2}{|c|}{$\left(2.65 \mathrm{e}^{-4}\right)$} & \multicolumn{2}{|c|}{$\left(3.3 \mathrm{e}^{-4}\right)$} & \multicolumn{2}{|c|}{$\left(2.22 \mathrm{e}^{-4}\right)$} \\
\hline \multirow[t]{2}{*}{$\mathrm{u} * \mathrm{H}$} & \multicolumn{2}{|c|}{$-7.04 e^{-7}$} & \multicolumn{2}{|c|}{$6.94 \mathrm{e}^{-6} * * *$} & \multicolumn{2}{|c|}{$-3.55 e^{-5} * *$} & \multicolumn{2}{|c|}{$-1.98 \mathrm{e}^{-6 * *}$} \\
\hline & \multicolumn{2}{|c|}{$\left(2.68 e^{-7}\right)$} & \multicolumn{2}{|c|}{$\left(1.72 \mathrm{e}^{-6}\right)$} & \multicolumn{2}{|c|}{$\left.1.28 e^{-5}\right)$} & \multicolumn{2}{|c|}{$\left(5.73 \mathrm{e}^{-6}\right)$} \\
\hline $\mathrm{R}^{2}$ & 0.42 & 0.61 & 0.43 & 0.65 & 0.48 & 0.69 & 0.42 & 0.63 \\
\hline $\begin{array}{c}\text { Sample } \\
\text { size }\end{array}$ & 382 & 382 & 2177 & 2177 & 1905 & 1905 & 3929 & 3929 \\
\hline
\end{tabular}

Note: D represents whether it is a residential land that can be settled down, $\mathrm{u}$ represents the distance to the urban center, $\mathrm{u}^{*} \mathrm{Y}$ represents the cross term of distance and income, and $\mathrm{u}^{*} \mathrm{H}$ represents the cross term of distance and population size. $* * *, * *, *$ and. indicates the significance level of the statical result at $0.1 \%, 1 \%, 5 \%$ and $10 \%$, respectively, with standard errors in brackets.

\section{Comparison to Similar Works}

Hu et al. (2014) used the hedonic price model and the housing price data of Nanjing to study the amenity of convenience in transportation. They found that the proximity of the home to the workplace would significantly increase the housing price. There are other similar literature measuring the amenity of environmental transportation, and this is the first time to use the hedonic price model to measure the amenity of urban public services represented by household registration, which is highly innovative. Wang Xuchun et al. (2018) studied the economic value attached to urban household registration from the perspective of marriage matching using the survey data of China family tracking survey (CFPS) in 2012. The study found that female who have urban household registration (relative to rural) can be replaced by 4 to 5 years of education, and male's urban household registration can be replaced by their disposable annual income of 24 to 27 million. The calculation method of that journal is also novel, but the author of that journal focuses on the differences 
between rural and urban areas, and this essay focuses on the differences between cities.

\section{Summary and Discussion}

In this paper, the economic value of public services represented by urban household registration is calculated by using the price difference between land that can be settled and land that cannot be settled. This kind of inequity not only results in the gap and people's sense of unfairness, but also damages the free flow of elements and economic efficiency. In the process of rapid urbanization, the agglomeration of population to big cities is a stage that all developed countries have experienced in the history of economy, and also a stage of rapid economic development. The existing literature and our research show that the government's intervention in the economy should be targeted: the agglomeration effect and advantages of large cities should be utilized, and the population size should not be deliberately limited. This is especially the case when the resident population of Beijing, Shanghai, Guangzhou, and Shenzhen is still far less than that of international metropolises such as New York and Tokyo. On the other hand, the supply of public goods cannot be too concentrated in large cities, there is greater needs of financial investment in education and medical services in small and medium-sized cities. We need to continue to narrow the regional public service gap on the supply side, so that the urban privileges behind the household registration gradually disappear, so that the household registration system can return to the original meaning of the registered population living conditions and mobile information, and the coordinated development of large and small cities. Of course, in this process, the benefit of education investment in small and medium-sized cities may be diluted by large cities. This in turn requires the central government to do a good job in financial transfer, utilizing the institutional advantages of the social significance of our country's characteristics, and let the development of the big cities feed the small cities. At present, there are some changes in the policies, but the results achieved, and the implementation efforts are not enough. In the future, the reform will be further deepened. 


\section{References}

[1] Albouy, D. and Stuart, B.A. (2020). Urban population and amenities: the neoclassical model of location. International Economic Review, 61, 1, pp. 127158.

[2] Braden, J.B. and Kolstad, C.D. (1991). Measuring the demand for environmental quality, Elsevier.

[3] Brookshire, D.S., Thayer, M.A., Schulze, W.D. and d'Arge, R.C. (1982). Valuing Public Goods: A Comparison of Survey and Hedonic Approaches. The American Economic Review, 72, 1, pp. 165-177.

[4] Cameron, A.C. and Miller, D.L. (2015). A practitioner's guide to clusterrobust inference. Journal of human resources, 50, 2, pp. 317-372.

[5] Cheng, T. and Selden, M. (1994). The Origins and Social Consequences of China's Hukou System. The China Quarterly, 139, pp. 644-668.

[6] Clawson, M. and Knetsch, J.L. (1966). Economics of Oufdoor Recreation, HeinOnline.

[7] Dwyer, J.F., Peterson, G.L. and Darragh, A.J. (1983). Estimating the value of urban forests using the travel cost method. Journal of Arboriculture, 9, 7, pp. 182-185.

[8] Garrod, G.D. and Willis, K.G. (1992). Valuing goods' characteristics: An application of the hedonic price method to environmental attributes. Journal of Environmental Management, 34, 1, pp. 59-76.

[9] Glaeser, E.L., Kolko, J. and Saiz, A. (2001). Consumer city. Journal of Economic Geography, 1, 1, pp. 27-50.

[10] Gottlieb, P.D. (1995). Residential Amenities, Firm Location and Economic Development. Urban Studies, 32, 9, pp. 1413-1436.

[11] Graves, P.E. (1983). Migration with a composite amenity: the role of rents. Journal of Regional Science, 23, 4, pp. 541-546.

[12] Griliches, Z. (1971). Price indexes and quality change: Studies in new methods of measurement, Harvard University Press.

[13] Hausman, J.A. (2012). Contingent valuation: A critical assessment, Elsevier.

[14] Howie, P., Murphy, S.M. and Wicks, J. (2010). An Application of a Stated Preference Method to Value Urban Amenities. Urban Studies, 47, 2, pp. 235256.

[15] Hu, H., Geertman, S. and Hooimeijer, P. (2014). Amenity value in postindustrial Chinese cities: the case of Nanjing. Urban Geography, 35, 3, pp. 420-439.

[16] Lewis, W.A. (1954). Economic development with unlimited supplies of labour.

[17] Liang, R. and Tang, Y. (2008). Tiebout model in local public goods supply. World Economy, 3, 10, pp. 71.

[18] Liao, L. and Wang, C. (2019). Urban amenity and settlement intentions of rural-urban migrants in China. PloS one, 14, 5, pp. e0215868. 
[19] Liu, J. and Wei, H. (2019). The impact of urban public services on the willingness of permanent migration of floating population. Economic Management, 41, 11, pp. 20-37.

[20] Mathur, V.K. and Stein, S.H. (2005). Do amenities matter in attracting knowledge workers for regional economic development?*. Papers in Regional Science, 84, 2, pp. 251-269.

[21] McNulty, R.H., Jacobson, D.R. and Penne, R.L. (1985). The economics of amenity: Community futures and quality of life: a policy guide to urban economic development, Pub Center Cultural Resources.

[22] Parsons, G.R. (1990). Hedonic prices and public goods: An argument for weighting locational attributes in hedonic regressions by lot size. Journal of Urban Economics, 27, 3, pp. 308-321.

[23] Randall, T.A. (2008). Preferences of Suburban Residents in Thunder Bay, Ontario Towards Neighbourhood Intensification and Rediversification. Canadian Journal of Urban Research, 17, 2, pp. 28-56.

[24] Rosen, S. (1974). Hedonic Prices and Implicit Markets: Product Differentiation in Pure Competition. Journal of Political Economy, 82, 1, pp. 34-55.

[25] Smith, V.K., Desvousges, W.H. and Fisher, A. (1986). A comparison of direct and indirect methods for estimating environmental benefits. American Journal of Agricultural Economics, 68, 2, pp. 280-290.

[26] Smith, V.K. and Kopp, R.J. (1980). The Spatial Limits of the Travel Cost Recreational Demand Model. Land Economics, 56, 1, pp. 64-72.

[27] Sorg, C.F. and Loomis, J.B. (1984). Empirical estimates of amenity forest values: a comparative review. General Technical Report, Rocky Mountain Forest and Range Experiment Station, USDA Forest Service, No. RM-107, pp. $\mathrm{i}+23 \mathrm{pp}$.

[28] Tyrväinen, L. and Väänänen, H. (1998). The economic value of urban forest amenities: an application of the contingent valuation method. Landscape and Urban Planning, 43, 1, pp. 105-118.

[29] Venkatachalam, L. (2004). The Contingent Valuation Method: A Review Environmental Impact Assessment Review No. 24.

[30] Walsh, R.G., Bjonback, R.D., Aiken, R.A. and Rosenthal, D.H. (1990). Estimating the public benefits of protecting forest quality. Journal of Environmental Management, 30, 2, pp. 175-189.

[31] Wang, X. and Zhong, X. (2018). Value of HuKou from marriage matching: evidence from CFPS. Journal of economics. Journal of Economics, 5, 1, pp. 150-186.

[32] Xia, Y. and Lu, M. (2015). "three relocation of Mencius" between cities: A Study on the impact of public services on labor flow. Management World, 1078-90.

[33] Zhao, P. and Howden-Chapman, P. (2010). Social inequalities in mobility: the impact of the hukou system on migrants' job accessibility and commuting costs in Beijing. International Development Planning Review, 32, 3-4, pp. 363-385. 
[34] Zhu, Y. and Chen, W. (2010). The settlement intention of China's floating population in the cities: recent changes and multifaceted individual-level determinants. Population, Space and Place, 16, 4, pp. 253-267. 